\title{
Original Article (short paper) \\ Aerobic exercise training induces superior cardioprotection following myocardial ischemia reperfusion injury than a single aerobic exercise session in rats
}

\author{
Juliana Pereira Borges \\ Guilherme de Oliveira França \\ Universidade Estadual do Rio de Janeiro, Rio de Janeiro, RJ, Brasil \\ Mariana Delgado Cruz \\ Rômulo Lanza \\ Alessandro Rodrigues do Nascimento \\ Marcos Adriano Lessa \\ Instituto Oswaldo Cruz, Rio de Janeiro, RJ, Brasil
}

\begin{abstract}
Aim: To compare the amount of cardioprotection induced by a single exercise session with those achieved after an 8-week aerobic exercise training following ischemia reperfusion injury in rats. Methods: Twenty-five male Wistar rats $(250-300 \mathrm{~g})$ were assigned into a group submitted to physical training (TR; $\mathrm{n}=12)$ or a single maximal exercise session (EXE; n=13). Following sedentarism or physical training ( 8 weeks, 5 sessions/wk, $1 \mathrm{~h} / \mathrm{session}$ at $70 \%$ of maximal speed) both groups performed a maximal exercise test. Then, groups were submitted to ischemia reperfusion injury $(30 \mathrm{~min} / \mathrm{lh})$ through an isolated heart protocol, in which left ventricle developed pressure was measured. Results: The TR group presented greater maximal oxygen consumption compared to the EXE group (77.25 $\pm 20.41 \mathrm{vs}$ $41.32 \pm 25.86 \mathrm{ml} / \mathrm{Kg} / \mathrm{min} ; \mathrm{P}=0.003)$. Regarding left ventricle developed pressure, no differences were detected between groups at baseline (TR: $89.78 \pm 24.40 v$ EXE: $81.37 \pm 31.84 \mathrm{mmHg} ; \mathrm{P}=0.48$ ). However, after reperfusion, the TR group presented superior intraventricular pressure than EXE group (37.94 \pm 18.34 vs $21.59 \pm 13.67 \mathrm{mmHg} ; \mathrm{P}=0.03)$. Conclusion: Eight-week aerobic training induced greater cardioprotection against ischemia reperfusion injury in rats compared to a single exercise session, due to an increased cardiac function. This suggests that exercise-induced cardioprotection is a multifactorial process that may involve different mediators according to the exercise duration.
\end{abstract}

Keywords: ischemia and reperfusion; aerobic exercise training; Langendorff.

\section{Introduction}

Epidemiologic studies indicate that cardiovascular diseases account for approximately $30 \%$ of all deaths in global population, turning it the leading cause of mortality worldwide ${ }^{1}$. Among the cardiovascular diseases, coronary artery disease (CAD) deserves special attention for its exponential increase in working-age adults ${ }^{1}$.

$\mathrm{CAD}$ is characterized for the reduction or interruption in coronary blood flow to a specific area of the cardiac muscle, which generates a myocardial ischemia ${ }^{2}$. Given that the reversibility and extension of the tissue damage are directly related to the duration of ischemia, the main therapeutic goal is to restore blood flow, allowing reperfusion as quickly as possible ${ }^{2}$. Although thrombolytic therapies and percutaneous coronary intervention are considered the treatment of choice for reducing the infarct area $^{3}$, they may cause several damages, including functional and structural impairments and cellular death. Together these alterations are commonly known as ischemia reperfusion (IR) injury ${ }^{2,3}$.

On the other hand, previous data reinforce the hypothesis that regular physical exercise induces cardioprotection ${ }^{4-8}$ and may reduce by up to $30 \%$ the mortality risk for cardiovascular diseases $^{6}$. Besides reducing cardiovascular disease risk factors, such as hypertension, diabetes mellitus, obesity and dyslipidemia ${ }^{7}$, it is well described that exercise also promotes cardioprotection against IR injury through a direct effect on the myocardium ${ }^{4,7,9,10}$.

In 1978, McElroy et al ${ }^{11}$ demonstrated that regular physical activity could provide cardioprotection. In that study, mice were subjected to physical training for 5 weeks and after irreversible occlusion of the left coronary artery, a $30 \%$ reduction of the infarcted area was observed in trained mice when compared with the sedentary control.

Interestingly, it has been already demonstrated that performing a single aerobic exercise session prior to an IR injury is sufficient to promote increment in cardiac output and ameliorate the cardiac function during and after a cardiac insult ${ }^{12}$. Nonetheless, considering that aerobic training implies several adaptations that are not observed after a single exercise session, it would be reasonable to assume that cardioprotection following exercise training is superior than that achieved after an unique exercise session. However, despite the lack of interventional settings focused on this specific matter, previous reviews claim that exercise-induced cardioprotection following few exercise sessions is similar than long-term physical training ${ }^{13,14}$. Clarifying 
this issue would be important as the potential mechanisms involved in exercise-induced cardioprotection are still largely debated; therefore, data in this sense could provide insights about these mechanisms that could help understanding them.

Therefore, the purpose of the present study was to compare the amount of cardioprotection induced by a single exercise session with that achieved after an 8-week aerobic exercise training following ischemia reperfusion injury in rats.

\section{Methods}

\section{Study Design}

All procedures described in the present study were approved by the Oswaldo Cruz Foundation Animal Welfare Committee (protocol \# LW-6/12) and are consistent with the USA National Institutes of Health Guide for the Care and Use of Laboratory Animals (NIH Publication No. 85-23, revised 1996). Twenty-five male Wistar rats (250-300g) were housed with controlled light (12:12 $\mathrm{h}$ light-dark cycle) and temperature $\left(22 \pm 1{ }^{\circ} \mathrm{C}\right)$ with free access to water and standard rat chow. Rats were randomly divided into a group submitted to an 8-week aerobic exercise training (TR; $\mathrm{n}=12$ ) or a single maximal aerobic exercise session (EXE; $\mathrm{n}=13$ ).

\section{Exercise Protocol}

Initially, the TR group was familiarized to treadmill running using a low-speed, motor-driven rodent treadmill (HT 2.0, Hectron Fitness Equipment, RJ, Brazil), on which the animals walked at $12 \mathrm{~m} / \mathrm{min}(0 \%$ grade) for $15 \mathrm{~min} /$ day on three consecutive days. Following this brief period of familiarization, a maximal exercise testing was performed in TR group to allow the exercise training prescription, which corresponded to 5 sessions/week of $60 \mathrm{~min} / \mathrm{session}$ on treadmill at $70 \%$ of maximal velocity for 8 weeks. Whilst the TR group was submitted to exercise training, the EXE group was maintained sedentary.

Twenty-four hours after the end of exercise training or sedentarism, maximal oxygen consumption $\left(\mathrm{VO}_{2 \max }\right)$ was measured in both groups during a maximal exercise testing. The exercise test protocol began with rats running at $10 \mathrm{~m} / \mathrm{min}(0 \%$ grade) with the treadmill speed increasing by $3 \mathrm{~m} / \mathrm{min}$ every $3 \mathrm{~min}$ until the animals could no longer maintain the desired running speed. $\mathrm{VO}_{2 \max }$ was measured by assessing the total airflow through the treadmill chamber and assessing the oxygen content of the expired gas using an electronic oxygen analyzer (AVS Projetos, SP, Brazil).

After $72 \mathrm{~h}$ of the exercise test, all animals underwent the surgical procedures to induce IR injury in isolated heart protocol. Knowing that exercise-induced cardioprotection persists practically unchanged for at least 9 days following an acute exercise $^{15}$, the $72 \mathrm{~h}$ between the exercise test and isolated heart preparation was chosen to preclude the influence of different acute effects other than cardioprotection per se in the results, such as post-exercise hypotension.

\section{Isolated Heart Preparation}

Following 72 hours of the maximal test, all animals, previously heparinized (500 i.u. $\mathrm{kg}-1$, I.P.), were killed by $\mathrm{CO}_{2}$ and cervical dislocation, and the excised hearts were immediately cannulated throughout the aorta according to the method of Langendorff and perfused via the coronary circulation at a constant flow rate of $10 \mathrm{ml} . \mathrm{min}-1$ with modified Krebs-Henseleit solution (mM: $118 \mathrm{NaCl}, 4.7 \mathrm{KCl}, 1.2 \mathrm{MgSO} 4,1.2 \mathrm{KH} 2 \mathrm{PO} 4,25 \mathrm{NaHCO}$, 10 glucose and $1.8 \mathrm{CaCl} 2, \mathrm{pH} 7.2$; gassed with $95 \% \mathrm{O} 2-5 \%$ $\left.\mathrm{CO} 2,36 \pm 0.5^{\circ} \mathrm{C}\right)$. A latex balloon was inserted in the left ventricle through the left atrium and adjusted to an end-diastolic pressure of $5-10 \mathrm{mmHg}$ at baseline. After $30 \mathrm{~min}$ of baseline perfusion, all hearts underwent a period of $30 \mathrm{~min}$ of sustained global ischemia followed by $1 \mathrm{~h}$ of reperfusion. Left ventricle pressure (monitored via the latex balloon) was recorded at baseline and at the end of the reperfusion period. For analysis, we used the ANCAD data recording software (AVS Projetos, São Paulo, Brazil).

\section{Statistical Analysis}

All results are expressed as mean $\pm \mathrm{SD}$. Comparisons between groups were performed with the Student $t$ test. Bonferroni post test was used to localize the significant differences. Correlation between left ventricle developed pressure and $\mathrm{VO}_{2 \max }$ was performed by Pearson correlation. P-values of $<0.05$ were considered statistically significant. All calculations were made by computer-assisted analysis using a commercially available statistical package (Graphpad Prism, Graphpad Software, San Diego, CA).

\section{Results}

\section{Biometric Parameters}

As seen in table 1, total (TR: $366.5 \pm 20.1 v s$. EXE: $362.5 \pm 28.5 \mathrm{~g}$; $\mathrm{P}=0.69$ ) and left ventricle weight (TR: $0.64 \pm 0.2$ vs. EXE: 0.65 $\pm 0.2 \mathrm{~g} ; \mathrm{P}=0.93$ ) were not different between groups.

Table 1: Biometric parameters

\begin{tabular}{cccc}
\hline & TR & EXE & P \\
\hline Total weight $(\mathrm{g})$ & $366.5 \pm 20.1$ & $362.5 \pm 28.5$ & 0.69 \\
Heart weight $(\mathrm{g})$ & $1.32 \pm 0.2$ & $1.35 \pm 0.2$ & 0.74 \\
Left ventricle weight $(\mathrm{g})$ & $0.64 \pm 0.2$ & $0.65 \pm 0.2$ & 0.93 \\
Tibia length (cm) & $5.2 \pm 0.2$ & $5.0 \pm 0.1$ & 0.06 \\
$\begin{array}{c}\text { Left ventricle weight/ tibia } \\
\text { length }\end{array}$ & $0.12 \pm 0.0$ & $0.13 \pm 0.0$ & 0.61 \\
\hline
\end{tabular}

Results are expressed as means $\pm \mathrm{SD}$. TR. group submitted to exercise training; EXE. group submitted to a single exercise session. 


\section{Maximal Exercise Capacity}

Table 2 presents the maximal exercise testing results. The TR group showed higher distance (546.14 $\pm 141.84 v s .263 .22 \pm$ $65.91 \mathrm{~m} ; \mathrm{P}<0.001)$, maximal velocity ( $35.0 \pm 3.5$ vs. $25.0 \pm 3.0$ $\mathrm{m} / \mathrm{seg} ; \mathrm{P}<0.001)$ and duration $(28 \pm 4$ vs. $18 \pm 3 \mathrm{~min} ; \mathrm{P}<0.001)$ than the EXE group. As expected, the TR group showed greater $\mathrm{VO}_{2 \max }$ than the EXE group $(77.25 \pm 20.41$ vs. $41.32 \pm 25.86 \mathrm{ml} /$ Kgmin; $\mathrm{P}=0.003$; Figure 1).

Table 2: Parameters obtained in maximal exercise testing in experimental groups.

\begin{tabular}{lllc}
\hline & \multicolumn{1}{c}{ TR } & \multicolumn{1}{c}{ EXE } & P \\
\hline Distance (m) & $546.14 \pm 141.84$ & $263.22 \pm 65.91$ & $<0.001$ \\
$\begin{array}{l}\text { Maximal velocity } \\
(\mathrm{m} / \mathrm{sec})\end{array}$ & $35.0 \pm 3.5$ & $25.0 \pm 3.0$ & $<0.001$ \\
Duration (min) & $28 \pm 4$ & $18 \pm 3$ & $<0.001$ \\
\hline
\end{tabular}

Results are expressed as means $\pm \mathrm{SD}$. TR. group submitted to exercise training; EXE. group submitted to a single exercise session.

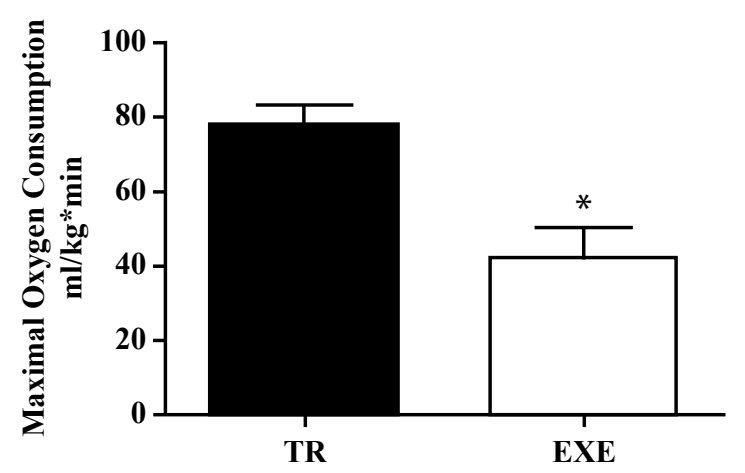

Figure 1: Maximal oxygen consumption in animals exercised for eight weeks (TR) and a single aerobic exercise session (EXE). $* \mathrm{P}=0.003$.

\section{Cardiac Function}

Left ventricle developed pressure in baseline condition did not differ between groups (TR: $89.78 \pm 24.40 v s$. EXE: 81.37 $\pm 31.84 \mathrm{mmHg}$; $\mathrm{P}=0.48$; Figure 2). However, after $60 \mathrm{~min}$ of reperfusion, the TR group presented superior left ventricle developed pressure in comparison to the EXE group (37.94 \pm 18.34 vs $21.59 \pm 13.67 \mathrm{mmHg}$; $\mathrm{P}=0.03$; Figure 2). There was no correlation between left ventricle developed pressure obtained at the end of reperfusion and $\mathrm{VO}_{2 \max }$ in the TR and EXE groups $(\mathrm{P}=0.30$ and $\mathrm{P}=0.11$; respectively; Figure 3$)$.

\section{Discussion}

The aim of the present study was to compare the amount of cardioprotection induced by a single exercise session with that achieved after an 8-week aerobic exercise training following ischemia reperfusion injury in rats. In this sense, our major finding was that the long-term training provided greater cardiac function measured through the left ventricle developed pressure, in comparison to a single exercise session following IR injury. In addition, we also observed a greater maximal exercise capacity in trained $v s$. single-exercised rats that was not correlated to the cardiac function. Therefore, our data support the idea that besides the benefits in cardiorespiratory function, exercise training plays a key role in protecting the heart after a myocardial insult as well.

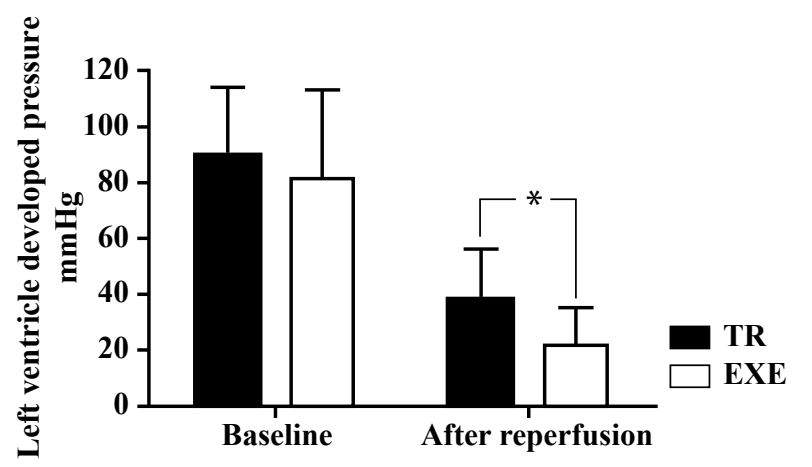

Figure 2: Left ventricle developed pressure in animals exercised for eight weeks (TR) and for a single session (EXE) at baseline and following ischemia reperfusion injury. ${ }^{*} \mathrm{P}=0.03$.

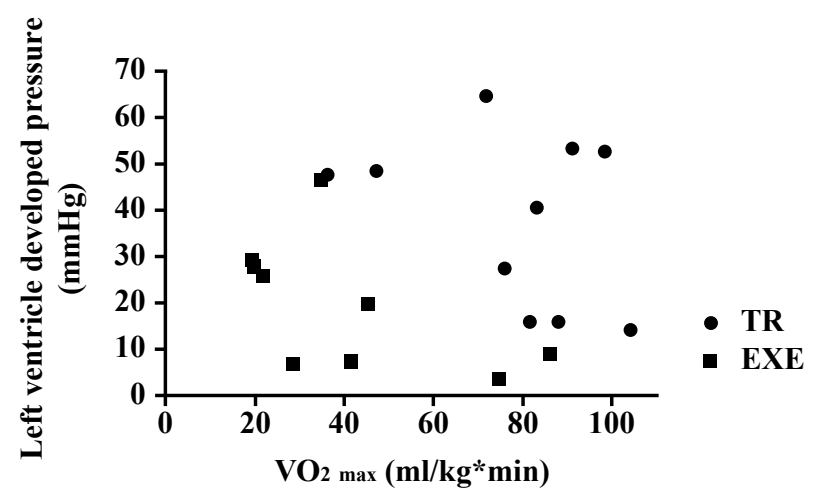

Figure 3: Correlation between left ventricle developed pressure obtained at the end of reperfusion and maximal oxygen consumption $\left(\mathrm{VO}_{2 \max }\right)$ in animals exercised for eight weeks $(\mathrm{TR} ; \mathrm{P}=0.30)$ and for a single session (EXE; $\mathrm{P}=0.11$ ).

Regarding the duration of exercise training, several previous studies have demonstrated that 8 to 12 weeks of exercise provide myocardial protection against IR injury in rats ${ }^{16-18}$. Meanwhile, it is also well documented that few exercise sessions of $60 \mathrm{~min}$ alter the cardioprotection phenotype ${ }^{9,18}$. Hamilton et $\mathrm{al}^{19}$ showed that five exercise sessions reduce the incidence of ventricular arrhythmias after IR injury in vivo. Similarly, Demirel et at ${ }^{12}$ assessed the cardiac function following IR injury of rats exercised for $60 \mathrm{~min} /$ day during 3 or 5 days at 60 or $70 \%$ of $\mathrm{VO}_{2 \max }$ (respectively) and observed that exercised rats maintained superior intraventricular pressure than sedentary rats. Although it is already clear that short-term exercise provides cardioprotection, so far no original study compared the protective effect 
induced by long and short-term exercise. Considering that the potential mechanisms involved in this response are still largely debated, data in this sense could provide insights regarding these mechanisms that could help clarifying this issue. Given that our experiments reveal for the first time that 8-week exercise training provides greater cardioprotection against IR injury than a single exercise session, some assumptions in regards to the mechanisms involved in this response could be raised.

Considering that exercise-induced cardioprotection occurs even after few exercise sessions, several adaptations exclusively observed after long-term training ( 8 to 12 weeks) are frequently neglected as mechanisms of cardioprotection, such as increased collateral circulation ${ }^{20}$. Indeed, these training-induced adaptations probably are not a prerequisite to achieve cardioprotection, but given our results of increased cardiac function of long-term training following IR injury, they could minimally play a role in this response. This reinforces the hypothesis that exerciseinduced cardioprotection is a multifactorial process or even that it involves different mediators according to the exercise duration.

To illustrate this, pertinent literature documents well that aerobic training causes an enhancement in the antioxidant enzyme activity in various tissues ${ }^{21}$. This is an physical training adaptation process that only happens because of the transient release of reactive oxygen species during exercise sessions, acting as signaling molecules ${ }^{21}$. This stimulates the gene expression and, hence, increases production of key antioxidant enzymes that help minimizing the oxidative stress process involved in IR injuries $^{22-25}$. Therefore, it is feasible to think that long-term training leads to greater amount of antioxidant enzymes production than acute exercise, which could justify the superior cardioprotection observed after exercise training. Another potential mechanism largely discussed in exercise-induced cardioprotection is the change in the coronary arteries, which includes increased conduit artery diameters, arteriolar densities, and diameters of $\operatorname{arteriolar}^{26}$. Considering that this adaptation requires several weeks of exercise training ${ }^{27}$, it could also account for our results.

As in relation to the exercise training intensity, previous data have demonstrated that this is an important issue when it comes to exercise-induced cardioprotection effect ${ }^{8,28}$. For instance, Starnes et $\mathrm{al}^{28}$ have found that 16 weeks of exercise training bellow 55 to $60 \%$ of $\mathrm{VO}_{2 \max }$ did not attenuate the damage caused by IR injury. On the other hand, Lennon et al. ${ }^{8}$ have concluded that exercise training at low $\left(50 \%\right.$ of $\left.\mathrm{VO}_{2 \max }\right)$ and moderate $\left(70 \%\right.$ of $\left.\mathrm{VO}_{2 \max }\right)$ intensity are equally protective. In this sense, in our study, we chose to apply the aerobic exercise training at $70 \%$ of maximal velocity (which corresponds approximately to $70 \%$ of $\mathrm{VO}_{2 \cos }{ }^{29}$ ) to ensure the cardioprotection afforded by exercise training.

The results of the present study should be interpreted considering certain limitations. First, the major limitation is the lack of a control group not submitted to exercise. Data in this sense would establish reference values and subsequently allow a more precise conclusion upon the acute exercise-induced cardioprotection. However, although we cannot assume that acute exercise induced cardioprotection in comparison to sedentarism, the lack of a control group did not jeopardize the comparison between the cardioprotective effect between short and long-term exercises, which is the major aim of the present study. Second, the assessment of tissue damage following IR injury, such as myocardial infarct size, would contribute to our results. Nonetheless, maintaining cardiac function is a key component involved in cardioprotection.

In addition, marked physiological differences are notably observed between different species; thus, direct extrapolation of these findings from rats to humans should be approached with caution. Nonetheless, experimental settings investigating issues related to IR injury are well accepted due to the difficulty in developing such studies with humans.

\section{Conclusion}

Our results indicate that eight weeks of exercise training lead to greater cardioprotection against IR injury in rats due to an increased cardiac function than a single exercise session. This reinforces the hypothesis that exercise-induced cardioprotection is a multifactorial process that may involve different mediators according to the exercise duration. However, further research is necessary to obtain more consistent conclusions, especially in regards to the mechanisms involved in short and long-term exercise-induced cardioprotection.

\section{References}

1. Go AS, Mozaffarian D, Roger VL, Benjamin EJ, Berry JD, Blaha MJ, et al. Heart disease and stroke statistics--2014 update: a report from the American Heart Association. Circulation. 2014;129(3):e28-e292.

2. Evora PR, Pearson PJ, Seccombe JF, Schaff HV. Ischemiareperfusion lesion. Physiopathologic aspects and the importance of the endothelial function. Arq Bras Cardiol. 1996;66(4):239-45.

3. Hausenloy DJ, Yellon DM. Myocardial ischemia-reperfusion injury: a neglected therapeutic target. J Clin Invest. 2013;123(1):92-100.

4. Powers SK, Quindry JC, Kavazis AN. Exercise-induced cardioprotection against myocardial ischemia-reperfusion injury. Free Radic Biol Med. 2008;44(2):193-201.

5. Ferdinandy P, Schulz R, Baxter GF. Interaction of cardiovascular risk factors with myocardial ischemia/reperfusion injury, preconditioning, and postconditioning. Pharmacol Rev. 2007;59(4):418-58.

6. Berlin JA, Colditz GA. A meta-analysis of physical activity in the prevention of coronary heart disease. Am J Epidemiol. 1990;132(4):612-28.

7. Powers SK, Lennon SL, Quindry J, Mehta JL. Exercise and cardioprotection. Curr Opin Cardiol. 2002;17(5):495-502.

8. Lennon SL, Quindry JC, French JP, Kim S, Mehta JL, Powers SK. Exercise and myocardial tolerance to ischaemia-reperfusion. Acta Physiol Scand. 2004;182(2):161-9.

9. Dickson EW, Hogrefe CP, Ludwig PS, Ackermann LW, Stoll LL, Denning GM. Exercise enhances myocardial ischemic tolerance via an opioid receptor-dependent mechanism. Am J Physiol Heart Circ Physiol. 2008;294(1):H402-8. 
10. Golbidi S, Laher I. Molecular mechanisms in exercise-induced cardioprotection. Cardiol Res Pract. 2011;2011:972807.

11. McElroy CL, Gissen SA, Fishbein MC. Exercise-induced reduction in myocardial infarct size after coronary artery occlusion in the rat. Circulation. 1978;57(5):958-62.

12. Demirel HA, Powers SK, Zergeroglu MA, Shanely RA, Hamilton $\mathrm{K}$, Coombes J, et al. Short-term exercise improves myocardial tolerance to in vivo ischemia-reperfusion in the rat. J Appl Physiol (1985). 2001;91(5):2205-12.

13. Powers SK, Sollanek KJ, Wiggs MP, Demirel HA, Smuder AJ. Exercise-induced improvements in myocardial antioxidant capacity: the antioxidant players and cardioprotection. Free Radic Res. 2014;48(1):43-51.

14. Kavazis AN. Exercise preconditioning of the myocardium. Sport Med. 2009;39(11):923-35.

15. Lennon SL, Quindry J, Hamilton KL, French J, Staib J, Mehta JL, et al. Loss of exercise-induced cardioprotection after cessation of exercise. J Appl Physiol (1985). 2004;96(4):1299-305.

16. Libonati JR, Gaughan JP, Hefner CA, Gow A, Paolone AM, Houser SR. Reduced ischemia and reperfusion injury following exercise training. Med Sci Sport Exercise. 1997;29(4):509-16.

17. Libonati JR, Kendrick ZV, Houser SR. Sprint training improves postischemic, left ventricular diastolic performance. J Appl Physiol (1985). 2005;99(6):2121-7.

18. Soufi FG, Saber MM, Ghiassie R, Alipour M. Role of 12-week resistance training in preserving the heart against ischemiareperfusion-induced injury. Cardiology journal. 2011;18(2):140-5.

19. Hamilton KL, Quindry JC, French JP, Staib J, Hughes J, Mehta JL, et al. MnSOD antisense treatment and exercise-induced protection against arrhythmias. Free Radic Biol Med.

20. Wiggs MP, Duarte AF, Powers SK. Exercise can protect against a broken heart. Curr Sports Med Rep. 2015;14(1):6-8.

21. Gomes EC, Silva AN, de Oliveira MR. Oxidants, antioxidants, and the beneficial roles of exercise-induced production of reactive species. Oxid Med Cell Longev. 2012;2012:756132.

22. Borges JP, Lessa MA. Mechanisms Involved in Exercise-Induced Cardioprotection: A Systematic Review. Arq Bras Cardiol. 2015;105(1):71-81.
23. Powers SK, Demirel HA, Vincent HK, Coombes JS, Naito H, Hamilton KL, et al. Exercise training improves myocardial tolerance to in vivo ischemia-reperfusion in the rat. Am J Physiol. 1998;275(5 Pt 2):R1468-77.

24. Hamilton KL, Powers SK, Sugiura T, Kim S, Lennon S, Tumer $\mathrm{N}$, et al. Short-term exercise training can improve myocardial tolerance to $\mathrm{I} / \mathrm{R}$ without elevation in heat shock proteins. Am J Physiol Heart Circ Physiol. 2001;281(3):H1346-52.

25. Hamilton KL, Staib JL, Phillips T, Hess A, Lennon SL, Powers SK. Exercise, antioxidants, and HSP72: protection against myocardial ischemia/reperfusion. Free Radic Biol Med. 2003;34(7):800-9.

26. Powers SK, Smuder AJ, Kavazis AN, Quindry JC. Mechanisms of exercise-induced cardioprotection. Physiology (Bethesda). 2014;29(1):27-38.

27. White FC, Bloor CM, McKirnan MD, Carroll SM. Exercise training in swine promotes growth of arteriolar bed and capillary angiogenesis in heart. J Appl Physiol (1985). 1998;85(3):1160-8.

28. Starnes JW, Taylor RP, Ciccolo JT. Habitual low-intensity exercise does not protect against myocardial dysfunction after ischemia in rats. Eur J Cardiovasc Prev Rehabil. 2005;12(2):169-74.

29. Lawler JM, Powers SK, Hammeren J, Martin AD. Oxygen cost of treadmill running in 24-month-old Fischer-344 rats. Med Sci Sports Exerc. 1993;25(11):1259-64.

\section{Corresponding author}

Juliana Pereira Borges

Laboratório de Atividade Física e Promoção à Saúde (LABSAU)

Rua São Francisco Xavier, 524, sala 8133F, Maracanã, Rio de Janeiro, RJ.

Email: julipborges@gmail.com

Manuscript received on September 11, 2016

Manuscript accepted on November 07, 2016

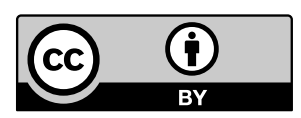

Motriz. The Journal of Physical Education. UNESP. Rio Claro, SP, Brazil - eISSN: 1980-6574 - under a license Creative Commons - Version 3.0 